\title{
ON THE CAUSES OF PALAEOCLIMATIC VARIATIONS AND OF THE ICE AGES IN PARTICULAR
}

\author{
By E. J. ÖPIK \\ (Armagh Observatory, Northern Ireland)
}

\begin{abstract}
A method of quantitative climatological analysis is developed by applying the principle of geometric similarity to the convective heat transport, which is assumed to vary with the $I^{\prime} \cdot 5$ power of temperature difference. The method makes possible the calculation of the change in the mean annual, or seasonal temperature, produced by a variation in insolation, cloudiness, snow cover, etc.

It is shown that the variations in the orbital elements of the earth cannot account for the phenomena of the ice ages; the chronology of the Quaternary, based on these variations, has no real foundation.

Palaeoclimatic variations are most probably due to variations of solar luminosity. These can be traced to periodical re-adjustments in the interior of the sun, produced by an interplay between nuclear reactions and gas diffusion, repeating themselves after some 250 million years. Complications from the outer envelope of the sun lead to additional fluctuations of a shorter period, of the order of roo, 000 years to be identified with the periodical advance and retreat of the glaciers during the Quaternary.

Calculations of the variations of luminosity in a star of solar mass substantiate this hypothesis.

Zusammenfassung. Eine quantitative Methode der klimatologischen Analyse ist entwickelt, indem das Prinzip von geometrischer Ahnlichkeit auf den konvektiven Wärmetransport angewandt ist, unter der Annahme, dass der letztere sich mit der $1 \cdot 5$ Potenz von Temperaturdifferenz ändert. Die Methode ermöglicht es, die Anderungen der mittleren Jahres- oder jahreszeitlichen Temperatur, die durch Variation der Sonnenstrahlung, Bewölkung, Schnee-
decke usw. bedingt sind, zu berechnen.

Es wird gezeigt, dass die Veränderlichkeit der Elemente der Erdbahn nicht im stande ist, das Phänomen der Eiszeiten zu erklären; die auf dieser Veränderlichkeit aufgebaute Zeitrechnung des Quartärs ist als unbegründet zu
bezeichnen.

Die paläoklimatischen Schwankungen sind höchst wahrscheinlich der Veränderlichkeit der Sonnenstrahlung zuzuschreiben. Dieselbe entspricht periodischen Umwälzungen im Sonneninnern, die durch das Zusammenspiel von Kernreaktionen und Gasdiffusion verursacht werden, und die sich nach jeweiligen 250 millionen Jahren wiederholen. Komplikationen seitens der Aussenhülle der Sonne erzeugen zusätzliche kürzere Schwankungen, von der Grössenordnung von 100000 Jahren, die mit dem periodischen Vorstossen und Zurückweichen des Eises während des Quartärs zu identifizieren sind.

Diese Hypothese wird durch Berechnungen der Lichtänderungen eines Sternes von Sonnenmasse unterstützt.
\end{abstract}

IN a series of publications, the writer has proposed to explain the ice ages by non-static changes in the sun, and has analysed some technical problems connected with this theory. ${ }^{5-8,9-12}$ The problems involved are on the border-line of climatology, geology, astronomy, and can be successfully tackled only with a broad method of approach.

The present study represents a synthesis and further development of these scattered researches, supplemented by a new climatological method, the essence of which consists in a quantitative solution for the third component of heat exchange-the convective transfer and storage of heat.

The results and conclusions may be summarized as follows.

A method of quantitative analysis of the climatic heat balance is developed, based on the principle that the three components of the heat exchange, insolation, radiation to space, and heat transfer by matter (transport from outside, and storage on the spot), reckoned per $\mathrm{cm} .{ }^{2}$ of a vertical column from the surface to the top of the atmosphere, are always in exact balance. Radiation and insolation are calculated in the usual way, the first from the absorption by water vapour and empirically adopted mean vertical distributions of temperature and moisture; it is assumed that these distributions depend solely upon the difference between the mean local and global surface temperatures. On this assumption, standard mean radiation curves, in dependence on the mean surface temperature, are calculated, separately for summer and winter, and for clear and cloudy sky.

The effective exponent of the surface-temperature dependence of radiation is small, because of the equalizing effect of the higher layers of the atmosphere where the temperature differences are reduced, or even inverted; the exponent depends upon how the comparison is made; for a simultaneous comparison of different localities (latitudes), $n=1 \cdot 2$ in winter and 0.2 in summer; for seasonal variation at the same locality, $n=\mathrm{I} \cdot 5(\mathrm{I} \cdot 4$ to $\mathrm{r} \cdot 9)$ for all latitudes; on sea it is larger, on 
land smaller. The above refers to a constant average global temperature. For the variation of the mean global temperature (e.g. from a variation in solar radiation), the relative vertical and horizontal distributions of temperature must remain the same, and the exponent follows more closely Stefan's law, $n=3.5$ for clear, 3.8 for cloudy sky, and 3.65 the mean for the Standard Earth.

To the radiation figures a correction factor of 0.915 is applied, to make the calculated global radiation and insolation equal. The mean global temperature decreases by $0.6^{\circ} \mathrm{C}$. per I per cent of cloudiness (Table I, p. 217); variations in cloudiness, either from the number of condensation and sublimation nuclei (meteoric and volcanic dust), or from the relative areas of land and sea, may have considerably affected the average temperature of the Earth in the past. ${ }^{3}$ There is no reason to suppose that moderate variations in the mean global temperature would affect the average cloudiness, when the distribution of land and sea and the relative humidity remain unaltered.

The difference between radiation and insolation gives $E$, the third component of the heat exchange, or the material heat transport (Table II, p. 217). For annual mean conditions, $E$ is purely convective transport and, as sucin, is proportional to the $1 \cdot 5$ power of the difference between the mean local temperature and a certain global parameter $\left(+13^{\circ} \mathrm{C}\right.$.) close to the mean global temperature; the proportionality factor, $B$, depends upon locality (latitude) and shows much similarity for the northern and southern hemispheres, as does $E$ itself, as far as averages over circles of latitude are concerned; this may be due to the interplay between friction and Coriolis deflection of the circulation, leading to a practically equal heat transport in the continental northern, and the oceanic southern hemispheres. Along the same circle of latitude, the annual convective transport varies but little, whereas the coefficient of proportionality $(B)$ shows large variations. For seasonal variation, $E=E_{1}+E_{2}$, where $E_{1}$ is the convective transport, $E_{2}$ the storage supply, assumed to depend on the first power of the seasonal deviation of surface air temperature from the annual mean, Table III (p. 218) gives values of $E_{2}$ for the summer in high latitudes.

With the weak dependence of radiation on surface temperature, the component $E$ is the chief stabilizing factor in determining the equilibrium temperature; the temperature response to a variation in insolation is a fraction only of the response in black-body equilibrium, the opposite of what has been assumed in the so-called Strahlungskurve speculations (Milankovitch and others) ${ }^{4}$ The variation of temperature relative to the global mean for constant solar luminosity is

$$
\delta T / T=(\Delta I / I) / K
$$

with the "stability factor"

$$
K=\left[\mathrm{r} \cdot 5 Q-\mathrm{I} \cdot{ }_{5} E_{1} T /\left(T-T_{1}\right)-E_{2} T /\left(T-T_{2}\right)\right] / I ;
$$

all three terms in the brackets are positive; here $Q=$ radiation, $I=$ insolation, $T_{1}$ about equals the global mean temperature minus $2^{\circ} \mathrm{C}$. (but may vary with the season), $T_{2}=$ annual mean; for the variation of the annual mean, $T=T_{2}, E_{2}=0$ and the third term in the brackets disappears. $\delta T$ is the differential variation, superimposed on a general variation of the global temperature (depending on solar luminosity) given by $\delta_{2} T$ for which the stability factor is 3.65 , nearly corresponding to Stefan's law. For constant global insolation and albedo only the differential variation remains, which is actually Milankovitch's case ; $K$ is then large, from 8 to 20 both for the seasonal (summer) and annual variation (Tables II and III), and the temperature variations small.

The influence of the variation of the obliquity and eccentricity of the Earth's orbit on annual and summer temperatures is calculated and the Strahlungskurve revised (Table IV, p. 218); the influence is small, in no proportion to the climatic fluctuations of the Quaternary. The summer temperatures affect the extent of glaciation (Table V, p. 2 I 8), but they are of secondary importance when the mean global temperature remains unaltered. The failure of Milankovitch's Strahlungskurve is underlined by two facts: the radiocarbon dating of the Mankato (Wisconsin) glaciation, which happens to coincide with a "high" of the Strahlungskurve; and the spread northwards of frost-sensitive trees during the interglacial periods, for which the Strahlungskurve predicts warmer summers, but colder winters. The attempt to explain the Quaternary fluctuations of climate solely 
by the variation of the orbital elements of the earth must be definitely rejected, and all chronological deductions from the Strahlungskurve must be stamped as illusory.

The change which has happened since the Tertiary represents a challenge which never was seriously answered by the adepts of the Strahlungskurve: "Even if we admit with Milankovitch and others that the advancing and retreating pulse of Quaternary glaciation reflects the combined fluctuations in the eccentricity $(e)$ and obliquity $(\epsilon)$ of the Earth's orbit, the absence of glaciation in the Tertiary and earlier remains still unexplained; the fact that Pilgrim did not dare to push his calculations back farther than 800,000 years before our era does not mean that the fluctuations did not exist before that; the variations of $e$ and $\epsilon$ depend upon planetary perturbations and are continuing certainly all the time the Earth and the solar system exist. Obviously something of a more fundamental change has occurred at the end of the Tertiary, and unless an explanation is given for the mere start of the first glaciation it may seem superfluous to argue about its subsequent course" (Ref. 6, p. 64). The answer consists in true variations of the mean temperature of the Earth, caused most probably by variations in the intensity of solar radiation, perhaps also by fluctuations in the mean cloudiness.

The self-catalytic effect of an ice cap in maintaining and increasing its size is investigated; former investigators ${ }^{3}$ have exaggerated its importance. The bipolar extent of ice caps, in dependence of the intensity of solar radiation, has been calculated (Table V, p. 218), with an estimated increase in cloudiness outside the ice cap (additional "pluvial" areas equal either to 15 per cent of the ice-covered, or to 15 per cent of the ice-free area, according to which is the smaller of the two), and without the increased cloudiness, which two cases are not radically different; and for two extreme cases of the Strahlungskurve ${ }^{4}$ where the difference is noticeable but insufficient to explain the vast amplitude of fluctuations of the Quaternary ice limit. These can be traced only to real fluctuations in global insolation. A glacial break-down will happen when the average ice limit reaches about lat. $50^{\circ} \mathrm{N}$., when the self-cooling effect would lead to an increase of the ice caps until they covered the whole Earth; for this to happen, the intensity of solar radiation must remain below 88 per cent of the present for at least 3000 years. When the average northern ice limit is north of $55^{\circ}$, the ice caps will be stable and change in strict response to global insolation; there would be no impulse for a small ice cap to grow spontaneously. The calculations are differentially tied up to the present-day climatic and geographical conditions.

With the present cloudiness, the climatic changes are accounted for by the following variation in solar radiation (or luminosity, $L$ ):

$\begin{array}{cccc}\text { Tertiary } & \text { Present } & \begin{array}{c}\text { Quaternary } \\ \text { Glacial Minimum }\end{array} & \begin{array}{c}\text { Quaternary } \\ \text { Interglacial }\end{array} \\ \mathrm{1} .09 & \mathrm{r} \cdot 00 & 0.87 & \mathrm{r} .02\end{array}$

For short periods, less than 2000 years, solar radiation may have dropped below 0.87 , without causing complete glaciation.

A physical model of long-term solar variability (during one major ice age) has been proposed by the writer ${ }^{6}$ and is worked out here in more detail. Further verification by calculations is required. The basic process is a convective disturbance in the interior of the sun, by which fresh atomic fuel (hydrogen) is transported inwards, towards the core, in which the hydrogen content has decreased from atomic reactions. The fresh supply of hydrogen temporarily increases the energy output until, from the ensuing expansion, a new state of equilibrium is approached, with a lower central temperature and a decreased rate of atomic reactions which corresponds to the equilibrium luminosity. During the expansion, the luminosity is lowered by an amount nearly equal to the excess of energy generation, and gradually approaches its equilibrium value. The period of decay (relaxation) of the disturbance, or the time of its decrease to a $\mathrm{x} / \boldsymbol{e}$ fraction of the initial value, is of the order of 500,000 years for the sun, for one sudden disturbance, or pulse. In the case of a prolonged continuous disturbance, the curve of variation of luminosity may correspond to the Pliocene-Quaternary deterioration of climate, stretching over millions of years. 
Repeated sharp pulses will lead to waves in the curve of luminosity, with a rapid decrease during a few thousand years after each pulse, and a gradual recovery.

The pulses of a deep-seated disturbance alone would be unable to account for the secondary fluctuations, as revealed by the repeated advance and retreat of glaciation during the Quaternary; the amplitude in luminosity would be too small and, although with a sudden onset, the retreat of the ice would have taken time intervals of over 100,000 years, instead of a few thousand years as actually was the case with the Mankato glaciation. Secondary disturbances in the outer layers of the sun are proposed as an explanation; these invariably follow the changes of structure produced by the deep-seated disturbance, and involve time intervals of the right order of magnitude; the pre-requisite of a luminosity effect is a stratification in the outer layers: the metal content in the subphotospheric convective region must be smaller than in the underlying radiative-equilibrium zone. A sample course of the variation in luminosity and structure during one ice age, produced by repeated deep-seated pulses, with secondary disturbances in the outer layers, has been calculated (Table VII, p. 218); the results are similar to what we know of the climatic changes in the Pliocene and Quaternary, as regards the amplitude and time-table of the fluctuations and allow of a considerable, although not arbitrary, freedom of adjustment. The time intervals involved in the variation of luminosity at the onset of the deep-seated pulses, and in the decay of the superficial disturbance, are both of the order of 2000 years.

The mechanism of the deep-seated disturbance is traced to an interplay between the progressive decrease in concentration of hydrogen in the core, caused by atomic reactions, and gas diffusion, chiefly of hydrogen. The atomic reactions lead to a core decreasing with time, and to a steep gradient of hydrogen concentration outside the core; along this gradient, gas diffusion causes hydrogen to flow inward, from a region comprising about 0.25 of the stellar mass. This has a double effect : first, in increasing the available store of hydrogen and lengthening the time scale of evolution; second, in increasing the metal content and opacity outside the core. The second effect leads ultimately to convective instability, which equalizes the metal content and temporarily produces a convective core of increased extent, hydrogen content and energy generation; this can be identified with the deep-seated disturbance leading to an ice age. After the disturbance has calmed down, a new course of evolution starts (with a somewhat smaller central hydrogen content than in the previous cycle), ending in a new disturbance after a certain interval of time. Repeated disturbances will be thus created, spaced by intervals of the order of several hundred million years. The almost periodic repetition of the major ice ages (Eocambrian, Permo-Carboniferous, Quaternary), with an apparent period of about 240 million years, can be explained in such a manner. The mixing is apt to proceed discontinuously, by a more or less sudden upset of a portion of a metastable layer, followed by gradual mixing over time intervals of $10^{5}-10^{6}$ years. ${ }^{8}$ Calculations are made for a model of solar mass, indicating that the mechanism of repeated disturbances will work even in the case of an initially uniform chemical composition (contrary to a former statement, in which gas diffusion was not allowed for); a slightly higher metal content in the core (0.0375 against 0.03 outside) will greatly enhance the ability to produce disturbances.

Table VI (p. 218) gives a sample calculation of the evolution of a solar mass. This is an improved version of former calculations 7,9 ; results of numerical integrations are used, corrected for gas diffusion. The calculation yields the luminosity of the sun, as it varies in the course of time on account of atomic reactions in the interior; the "normal" course of luminosity is given, free from the disturbances of the ice ages; the present-day normal luminosity is assumed equal to $1 \cdot 09$, or the same as for the Tertiary. The hypotheticäl mean temperature of the Earth is also calculated, assuming constant albedo and mean distance from sun, for radiation proportional to the 3.65 power of the temperature. The main feature is a gradual increase of solar luminosity and terrestrial temperatures, ending in a rapid catastrophic peak which brings the global temperature to $+125^{\circ} \mathrm{C}$. The timing of this peak is uncertain, as it depends upon the identification of the present stage of evolution of the sun (ro per cent hydrogen in the core); according to the table, the catastrophic heat wave begins about 1,100 million years from now (a former estimate was 600 
million years). This catastrophe corresponds to the transition from a "convective" to an "isothermic" structure of the core, and does not yet signify a "nova" outbreak. The qualitative feature of the luminosity increasing with time (at constant mass) is in itself an invariable property of evolution by conversion of hydrogen into helium ${ }^{5}$; the quantitative outcome depends upon the details of internal structure. The actual evolution will consist of a succession of periods of calm evolution, spaced by convective disturbances (ice ages).

The recurrence of secondary disturbances in the outer layers of a star (the sun) requires a certain process of recovery that makes the photospheric metal content smaller again, after it has increased through mixing during one ice age. Gas diffusion is definitely inadequate for this purpose. Accretion of hydrogen and helium gas, poor in metal content, may represent the agent of recovery. Estimates referring to accretion and loss of mass (from ion emission) are made, and upper limits to the variation of solar mass during geological time are given. In the energy balance of the sun, accretion must have played an utterly insignificant role.

The problems of Pre-Tertiary climate seem still to be best treated from the standpoint of basic permanence of the continents. ${ }^{1}$ The advantage of introducing continental drift for the explanation of glaciation in the upper Palaeozoic is outdone by the distribution of glaciation in the Cambrian, and of coral reefs in the whole Palaeozoic era (cf. Ref. 2). Palaeozoic ice sheets which occurred near the equator are not at all surprising, in view of our climatic analysis which indicates a major instability when solar radiation drops below the 88 per cent limit. In remote Archaic epochs this may have happened more readily, owing to the lower average intensity of solar radiation. The notion of a gradually "cooling" earth (climatically), still favoured by some geologists, must be definitely abandoned for all the time during which the internal heat of the earth was prevented by a solid crust from flowing out; the initial state must have borne more resemblance to a worldwide ice age, than to anything else.

A longer article on this subject is now in the press and will be published in Contributions from the Armagh Observatory, No. 9.

MS. received 29 October $195^{2}$

\section{R E F E R E N C E S}

I. Umbgrove, J. H. F. The pulse of the earth. Second edition. The Hague, Martinus Nijhoff, 1947.

2. Schwarzbach, Martin. Das Klima der Vorzeit. Stuttgart, F. Enke, 1950.

3. Brooks, C. E. P. Climate through the ages. Revised edition. London, Ernest Benn, 1949.

4. Köppen, W., and Wegener, A. Die Klimate der geologischen Vorzeit. Berlin, Gebr. Bornt

5. Öpik, E. J. Acta et Commentationes Universitatis Tartuensis (Dorpatensis), Series. Borntraeger, 1924.

5. Opik, M. J. Acta et Commentationes Universitatis Tartuensis (Dorpatensis), Series A, Vol. 33, No. $9,1938$.

7. - Monthly Notices of the Royal Astronomical Society, Vol. r ro, 1950, p. 48.

7. - Proceedings of the Royal Irish Academy, Series A, Vol. 54, 195 I, p. 49.

9. - Proceedings of the Royal Irish Academy, Series A Vol. I 10, r950, p. 559.

9. - Proceedings of the Royal Irish Academy, Series A, Vol. 53, 1949, p. 1.

10. - Monthly Notices of the Royal Astronomical Society, Vol. 11 I, 1951, p. 278.

11. - Publications de l'Observatoire Astronomique de l'Université de Tartu (Dorpat), Vol. 30, No. 4, 1938.

12. - Publications de l'Observatoire Astronomique de l'Université de Tartu (Dorpat), Vol. 31, No. $1,1943$.

\begin{tabular}{|c|c|c|c|c|c|}
\hline $\begin{array}{l}\text { Cloudiness, } \% \\
\text { Mean Global Temperature, }{ }^{\circ} \mathrm{C} . \ldots\end{array}$ & $\begin{array}{l}30 \\
25.9\end{array}$ & $\begin{array}{l}40 \\
21 \cdot 4\end{array}$ & $\begin{array}{l}50 \\
15.6\end{array}$ & $\begin{array}{l}60 \\
9.0\end{array}$ & $\begin{array}{l}70 \\
2 \cdot 3\end{array}$ \\
\hline
\end{tabular}

TABLE II

Annual Mean Components of Heat Exchange, $\mathrm{r}^{-3} \mathrm{cal} . / \mathrm{cm} .{ }^{2} \mathrm{sec}$., and Stability Factor, $\mathrm{K}$

\begin{tabular}{|c|c|c|c|c|c|c|c|}
\hline $\begin{array}{ll}\text { Latitude } & \text { North } \\
& I \\
& Q \\
& E \\
\text { Seasonal } & n \\
& K\end{array}$ & $\begin{array}{r}0^{\circ} \\
5.43 \\
4.60 \\
-0.83 \\
6.4\end{array}$ & $\begin{array}{r}20^{\circ} \\
5.80 \\
4.87 \\
-0.93 \\
1.6 \\
7.1\end{array}$ & $\begin{array}{r}30^{\circ} \\
5 \cdot 42 \\
4 \cdot 86 \\
-0.56 \\
1 \cdot 7 \\
7 \cdot 5\end{array}$ & $\begin{array}{r}50^{\circ} \\
3.74 \\
4.44 \\
+0.70 \\
1.4 \\
12.8\end{array}$ & $\begin{array}{r}60^{\circ} \\
2 \cdot 86 \\
4 \cdot 34 \\
+1 \cdot 48 \\
1 \cdot 4 \\
17 \cdot 2\end{array}$ & $\begin{array}{r}70^{\circ} \\
2 \cdot 26 \\
4 \cdot 23 \\
+1 \cdot 97 \\
x \cdot 7 \\
17 \cdot 2\end{array}$ & $\begin{array}{r}90^{\circ} \\
1.62 \\
4.11 \\
+2.49 \\
1.9 \\
19.8\end{array}$ \\
\hline
\end{tabular}


TABle III

Summer Mean Components of Heat Exchange and Stability Factor

\begin{tabular}{ccccr} 
& \multicolumn{4}{c}{$\begin{array}{c}\text { Summer Mean Components of Heat } \\
\text { North (July) }\end{array}$} \\
Latitude & $90^{\circ}$ & $80^{\circ}$ & $70^{\circ}$ & $60^{\circ}$ \\
$I$ & 4.38 & 4.38 & 5.00 & 5.32 \\
$Q$ & 4.71 & 4.67 & 4.72 & 4.69 \\
$E_{1}$ & +0.96 & +0.92 & +0.60 & +0.22 \\
$E_{2}$ & -0.63 & -0.63 & -0.88 & -0.85 \\
$K$ & 8.1 & 9.1 & 8.8 & 8.9
\end{tabular}

$\begin{array}{rr} & \text { South } \\ 60^{\circ} & 70^{\circ} \\ 5.41 & 4.72 \\ 4.90 & 4.68 \\ +0.95 & +1.04 \\ -1.46 & -1.08 \\ 19.8 & 13.2\end{array}$

South (January)

$\begin{array}{rr}70^{\circ} & 80^{\circ} \\ 4.72 & 4.40 \\ 4.68 & 4.70 \\ +1.04 & +0.98 \\ 1.08 & -0.68 \\ 13.2 & 9.1\end{array}$

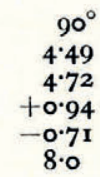

\section{TABLE IV}

Local Variation of Summer Temperature, $\delta T$, at $60^{\circ}$ North, from Variation in the Orbital Elements of the Earth, ${ }^{\circ}$. ; time in thousands of years before A.D. $185^{\circ}$

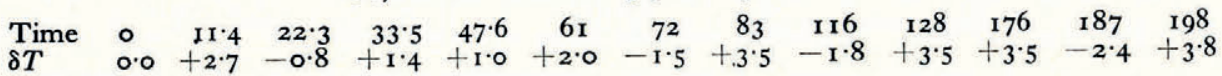

\section{TABLE V}

Solar Luminosity, $L$ (present $=\mathrm{I})$, and Extent of Glaciation

Orbital

Elements

Northern
Hemisphere

Ice Limit, Mean Latitude

$--($ no ice)
$90^{\circ} \mathrm{N}$.
$80^{\circ} \mathrm{N}$.
$70^{\circ} \mathrm{N}$.
$60^{\circ} \mathrm{N}$.
$50^{\circ} \mathrm{N}$.

A.D. 1850 Southern Hemisphere Ice Limit, Mean Latitude

$\begin{array}{ll}90^{\circ} \mathrm{S} . & 1 \cdot 10 \mathrm{r} \\ 76^{\circ} \mathrm{S} . & 1.046 \\ 65^{\circ} \mathrm{S} . & 0.996 \\ 62^{\circ} \mathrm{S} . & 0.964 \\ 50^{\circ} \mathrm{S} . & 0.900 \\ 42^{\circ} \mathrm{S} . & 0.885\end{array}$

$$
\begin{aligned}
& \text { Orbital } \\
& \text { Elements } \\
& \text { B.C. } 185,600 \\
& \text { "Northern } \\
& \text { Glacial"" }
\end{aligned}
$$
Southern Hemisphere Ice Limit

$\begin{array}{ll}90^{\circ} \mathrm{S} . & 1.096 \\ 87^{\circ} \mathrm{S} . & 1.080 \\ 69^{\circ} \mathrm{S} . & \mathrm{r} \cdot 029 \\ 65^{\circ} \mathrm{S} . & 0.994 \\ 54^{\circ} \mathrm{S} . & 0.920 \\ 46^{\circ} \mathrm{S} . & 0.901\end{array}$

Orbital

Elements B.c. 196,500

"Northern

Interglacial"

Southern Hemisphere Ice Limit

$90^{\circ} \mathrm{S}$.
$64^{\circ} \mathrm{S}$.
$59^{\circ} \mathrm{S}$.
$54^{\circ} \mathrm{S}$.
$4 \mathrm{I}^{\circ} \mathrm{S}$.
$32^{\circ} \mathrm{S}$.

$L$

$x \cdot 166$

I.006

$0.96 \mathrm{r}$

0.933

0.878

0.872

\section{Table VI}

Sample Course of Evolution of the Sun, from atomic reactions and gas diffusion, without the temporary disturbances of the ice-ages

$L=$ Solar Luminosity (present $=\mathrm{I}$ ); $t=$ Mean Temperature of Earth, ${ }^{\circ} \mathrm{C}$.; Time $=$ Millions of Years from Now $(-=$ before, $+=$ after $) ; X=\%$ of Hydrogen in the Convective Core of the Sun.

$\begin{array}{lccccccccc}X & 27.7 & 20.0 & 10.0 & 5.0 & 2.5 & 1.25 & 0.62 & 0.31 & 0.08 \\ \text { Time } & -3000 & -1510 & 0 & +660 & +920 & +1040 & +1092 & +1114 & +1122 \\ L & 0.92 & 1.00 & 1.09 & 1.15 & 1.20 & 1.26 & 1.41 & 1.67 & 3.25 \\ t & +9 & +15 & +22 & +26 & +30 & +34 & +43 & +59 & +125\end{array}$

\section{TABLE VII}

Calculated Sample Variation of Solar Luminosity ( $L$, units of equilibrium luminosity) during one major ice age

Time in Years; single asterisks = pulses; double asterisks $=$ secondary disturbances.

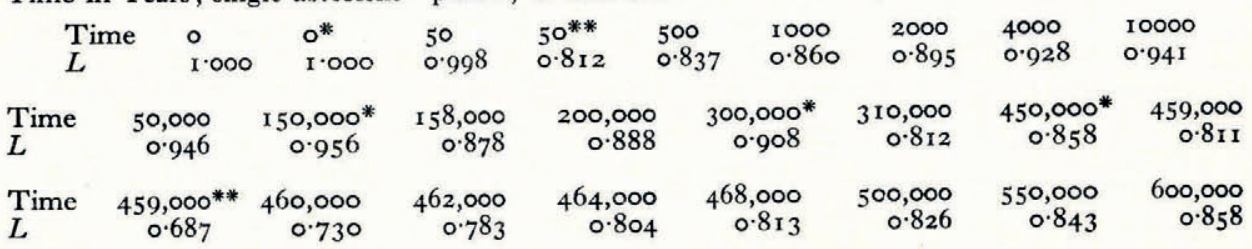

